\title{
TRATAMIENTO DE LA RESPONSABILIDAD PARENTAL EN EL REGLAMENTO 2201/2003. UN AVANCE HACIA LA INTEGRACIÓN Y ARMONIZACIÓN DEL DERECHO CIVIL EN EUROPA
}

\author{
Sillia Ortiz Herrera \\ Doctor en Derecho \\ Investigador Asociado del Instituto de Estudios Europeos \\ Universidad San Pablo CEU \\ Secretario Judicial
}

Resumen: El reglamento 2201/2003 representa un instrumento jurídico fundamental en el ámbito de la cooperación judicial en materia civil, dirigido a hacer realidad un espacio europeo de libertad, seguridad y justicia. El propósito de este artículo es poner de relieve los aspectos del Reglamento referentes a la responsabilidad parental y como se perfila este concepto desde una nueva perspectiva, que busca la protección del menor como valor fundamental y con relevancia propia respecto a la regulación de los procedimientos matrimoniales. Sin embargo, dado que la aplicación de las normas relativas a la responsabilidad parental frecuentemente surge en el contexto de los procedimientos matrimoniales, las instituciones europeas han considerado más apropiado incluir la regulación de ambas materias en un mismo Reglamento, en aras de alcanzar una eficacia óptima. Resulta especialmente destacable la importancia otorgada al objetivo de respetar el interés y beneficio del menor, constituyéndolo como un principio fundamental y superior, en consonancia con el artículo 24 Carta de los Derechos Fundamentales de la Unión Europea.

Palabras clave: Cooperación judicial civil en la Unión Europea. Reconocimiento mutuo y ejecución de resoluciones judiciales. Armoni- 
zación de normas procesales. Principio de confianza mutua. Reglamento 2201/2003. Ámbito material de aplicación. Evolución del derecho de familia. Interés superior del menor. Derechos fundamentales del menor. Concepto de responsabilidad parental. Concepto de derecho de custodia. Concepto de derecho de visita.

Abstract: The Regulation 2201/2203 represents an important mesure in the field of judicial cooperation in civil matters in order to ensure the objective of creating an area of freedom, security and justice. The aim of this paper is to emphasize the aspects of the Regulation that refers to the parental responsibility, and how the Regulation includes measures for the protection of the child, independently of any link with a matrimonial proceeding. However, since the application of the rules on parental responsability often arises in the context of matrimonial proceedings, the European institutions have considered more appropriate to have a single instrument for matters of divorce and parental responsibility. For the sake of this efficiency the Regulation 2201/2003 is elaborated. All measures established in the Regulation are shaped in the light of the best interests of the child, in particular, it seeks to ensure respect for the fundamental rights of the child as set out in Article 24 of the Charter of Fundamental Rights of the European Union.

Sumario. I- REFERENCIA AL MARCO NORMATIVO COMUNTARIO EN EL QUE SE INSERTA EL REGLAMENTO 2201/2003. II- EL REGLAMENTO 2201/2003. CARACTERES ESPECÍFICOS Y PRINCIPIOS RECTORES. III- ÁMBITO MATERIAL DE APLICACIÓN. APROXIMACIÓN GENERAL. IV-CONCEPTOS DEFINIDOS EN EL REGLAMENTO DE ESPECIAL SIGNIFICACIÓN: 1.CONCEPTO DE RESPONSABILIDAD PARENTAL. 2.CONCEPTO DE DERECHO DE VISITA. 3.CONCEPTO DE DERECHO DE CUSTODIA. V- CONCLUSIONES. VI- BIBLIOGRAFIA.

\section{REFERENCIA AL MARCO NORMATIVO COMUNTARIO EN EL QUE SE INSERTA EL REGLAMENTO 2201/2003}

Este entorno viene determinado fundamentalmente por la evolución en el tratamiento de la materia que se ha producido en los Tratados comunitarios. Inicialmente la regulación comunitaria de la cooperación judicial civil estaba limitada al artículo 220 del TCEE, actual artículo 293 TCE en el que se dispuso que los Estados miem- 
bros entablasen, cuando fuera necesario, negociaciones entre sí a fin de asegurar para sus nacionales la simplificación de las formalidades a que están sometidos el reconocimiento y la ejecución recíprocas de las decisiones judiciales y de los laudos arbítrales. Este precepto sirvió de base para la elaboración del Convenio relativo a la competencia judicial y a la ejecución de resoluciones judiciales en materia civil y mercantil firmado en Bruselas el 27 de septiembre de 1968. En aquel momento, se trataba de una cooperación entre Estados con fundamento en instrumentos comunitarios, pero no propiamente comunitaria.

Un paso ulterior en el proceso se inicia con el Tratado de Maastrich de 7 de febrero de 1992, que incluyó en el Tratado de la UE el Título VI dedicado a la cooperación judicial o «tercer pilar», en cuyo artículo K.3 se preveía la conclusión, en este ámbito, de Convenios internacionales entre los Estados Miembros. Por lo tanto, no se introdujo todavía la materia en el primer pilar o pilar comunitario, pero al amparo del Título VI se elaboraron iniciativas que terminaron en el proyecto de Convenio celebrado con arreglo al citado artículo, sobre la competencia, reconocimiento y la ejecución de resoluciones judiciales en materia matrimonial, conocido como Bruselas II. Este Convenio no llegó a entrar en vigor porque antes de finalizar el proceso de ratificaciones se modificó el régimen normativo, lo que permitió que se adoptara bajo la forma de Reglamento. Sin embargo, su elaboración tuvo como consecuencia positiva, el que se desarrollase un Informe Explicativo ${ }^{1}$ publicado en el DOCE C221 de 26 de julio de 1998, de gran utilidad para la interpretación y análisis del Reglamento en los aspectos en que su texto coincide con el del Proyecto de Convenio ${ }^{2}$.

La comunitarización se alcanza finalmente con el Tratado de Ámsterdam, al incluirse dentro del TCE un nuevo Título III bis. Esto supone la aplicación del sistema de fuentes del primer pilar, con el consiguiente avance en claridad y eficacia que ello comporta. Suprimida la internacionalización implícita en la regulación de la materia mediante la vía convencional, se han podido aplicar los ins-

1 Informe que se efectúa cuando lo que debe aprobarse es un Convenio.

2 Así lo afirma F.P. Puig Blanes, "Competencia judicial y foros de competencia en el Reglamento (CE) n. ${ }^{\circ} 2201 / 2003$ del Consejo, de 27 de noviembre de 2003, relativo a la competencia, el reconocimiento y la ejecución de resoluciones judiciales en materia matrimonial y de responsabilidad parental, por el que se deroga el Reglamento (CE) n. ${ }^{\circ} 1347 / 2000 »$, Cooperación judicial en materia de familia y relaciones parentales en la UE, Madrid: CGPJ, 2006, página 20. 
trumentos legislativos propios del ámbito comunitario, produciéndose con ello un cambio positivo hacia la agilidad en la adopción y modificación de medidas y hacia la armonización jurídica en todos los Estados miembros ${ }^{3}$.

Posteriormente, el Consejo Europeo de Tampere se caracterizó por el interés en la creación de un espacio judicial común eficaz ${ }^{4}$, para el que resultaba esencial la regulación del reconocimiento mutuo de las resoluciones judiciales como principio del derecho comunitario. El 30 de noviembre de 2000 fue adoptado por el Consejo, el Programa conjunto de la Comisión y del Consejo de medidas para la aplicación del principio de reconocimiento mutuo de resoluciones judiciales en materia civil y mercantil encaminado a la consecución de aquel objetivo, con la supresión del exequátur en las materias a que hacía referencia.

En la primera etapa de este programa, la Comisión presentó, concretamente en marzo de 2001, un documento de trabajo sobre el reconocimiento mutuo de resoluciones referentes al ámbito familiar y posteriormente una propuesta legislativa ${ }^{5}$, que completaba el Reglamento 1347/2000. Esta propuesta fue sustituida en mayo de 2002 por una nueva propuesta de Reglamento anunciada por la Comisión que pretendía la derogación del Reglamento Bruselas II y su ampliación ${ }^{6}$. Con esta base se fraguó el nuevo Reglamento cuya propuesta definitiva se publicó en el DOUE, el 23 de diciembre de 2003,

3 Véase sobre este aspecto A. Borrás Rodríguez, REDI, N. ${ }^{\circ} 2,1999$, páginas 383 y siguientes, E. Pérez Vera, «El Derecho internacional privado y la Unión Europea», La Unión Europea ante el siglo XXI: los retos de Niza (Actas de las XIX Jornadas de la Asociación Española de Profesores de Dereho Internacional y Relaciones internacionales), Madrid, BOE; 2003, páginas 173 y siguientes, P.A. de Miguel Asensio, "Integración europea y Derecho internacional privado», $R D C E$, N. $^{\circ} 2,1997$, páginas 413 y siguientes, M. Gardeñes Santiago, «El desarrollo del Derecho internacional privado tras el Tratado de Ámsterdam: los artículos $61 \mathrm{c})$ y $65 \mathrm{TCE}$ como base jurídica», $R D C E$, num. 11 , mayo-agosto 2002, páginas 231 y siguientes y J. Basedow, «The comunitarisation of the conflict of law under the Treaty of Amsterdam», CMLR, 2000, páginas $687 \mathrm{y}$ siguientes.

${ }^{4}$ Se buscó la constitución del espacio europeo de Justicia centrándose en tres ámbitos: la mejora del acceso a la Justicia en Europa, el reconocimiento mutuo de las decisiones judiciales y la convergencia en el ámbito del Derecho civil en los asuntos transfronterizos.

${ }^{5}$ Propuesta de Reglamento del Consejo relativo a la competencia, el reconocimiento y la ejecución de resoluciones judiciales en materia de responsabilidad parental, presentada por al Comisión el 6 de septiembre de 2001; COM (2001) 505 final2001/0204 (CNS); DOCE C-332 E, de 27 de noviembre de 2001, páginas 269 y siguientes.

6 COM (2002) 222, de 3 de mayo. 
respetando básicamente la de 2002, pero acogiendo alteraciones introducidas por los diversos Consejos Europeos.

El Tratado de Niza implicó un avance sustancial, consistente en la aplicación del mecanismo de la codecisión del artículo 251 del TCE para la adopción de las medidas de cooperación judicial en materia civil con repercusión transfronteriza, en virtud de la adición al artículo 67 de un nuevo apartado quinto.

El Consejo Europeo celebrado en Bruselas en noviembre de 2004, en el que se aprobó el Programa de La Haya, también conocido como Tampere $\mathrm{II}^{7}$, constituyó otro paso significativo, pues en sus trabajos se puso especial énfasis en destacar la influencia que tiene, en la vida diaria de los ciudadanos, el derecho civil y más específicamente el derecho de familia, por lo que se atribuyó gran importancia al desarrollo de la cooperación judicial en materia civil y a la culminación total del programa de reconocimiento mutuo adoptado en 2000. El Plan de Acción para la aplicación del Programa de La Haya fue aprobado en la reunión del Consejo de Ministros de Justicia e Interior de 3 de junio de $2005^{8}$, en el que se concretó el modo de consecución de estos objetivos.

No puede dejar de mencionarse el frustrado Tratado que establecía una Constitución para Europa, firmado en Roma el 29 de octubre de $2004^{9}$, ratificado por España tras el referéndum de 20 de febrero de 2005 y la aprobación por las Cortes Generales de la LO 1/2005 de 20 de mayo ${ }^{10}$.

La cooperación en materia civil aparecía recogida en el artículo III 269. Guiada por el principio del reconocimiento mutuo de las decisiones judiciales y extrajudiciales, implantaba una serie de ámbitos en los que debía desarrollarse la colaboración entre los Estados miembros. Además del reconocimiento mutuo de las resoluciones judiciales y su ejecución, se trataban aspectos procesales tendentes a la agilización de los trámites, como los referentes a la notificación y el traslado transfronterizos de documentos judiciales y extrajudiciales, o la compatibilidad de las normas aplicables en los Estados miembros en materia de conflictos de leyes, de jurisdicción y de procedimiento, pasando por el desarrollo de métodos alternativos de resolución de litigios y el apoyo a la formación de magistrados y personal al servicio de la Administración de justicia.

\footnotetext{
7 DOUE Serie C, 3-3-05.

8 COM 2005184 final.

9 DUE de 16-12-2004.

10 BOE de 21-5-2005.
} 


\section{EL REGLAMENTO 2201/2003. CARACTERES ESPECÍFICOS Y PRINCIPIOS RECTORES}

Para apreciar más certeramente el lugar que ocupa el Reglamento 2201/2003 en la regulación de las relaciones parentales y su ámbito material de aplicación, conviene reparar en la regulación reglamentaria que le sirve de precedente. Doctrinalmente ${ }^{11}$, se ha señalado al Reglamento 44/2001 (Bruselas I) como «el 'causahabiente' de la norma convencional verdaderamente constitutiva de la cooperación judicial en materia civil entre los países miembros de la Unión Europea, concretada en el Convenio de Bruselas de 27 de septiembre de $1968 »^{12}$. Sin embargo, por lo que respecta a los menores, el Reglamento Bruselas I se aplica para el reconocimiento y ejecución de las medidas que conciernen al patrimonio de los niños, pero no incide directamente en la protección de menores. Este sería el Reglamento a tener en cuenta en materia de reconocimiento y ejecución en un Estado miembro de la obligación de alimentos, aunque ésta esté vincu-

11 J.F. Cobo Sáenz, "El reconocimiento y ejecución de resoluciones judiciales, documentos públicos y acuerdos entre las partes con fuerza ejecutiva, en el Reglamento CE número 2201/03, (Bruselas II), relativo a la competencia judicial, el reconocimiento y la ejecución de resoluciones en materia matrimonial y de responsabilidad parental", Cooperación judicial en materia de familia y relaciones parentales en la UE, Madrid: CGPJ, 2006, página 59. Sobre el reglamento 44/2001, puede verse P Franzina, «Le condizioni di applicabilità del regolamento (CE) n. 44/2001 alla luce del parere 1/03 della Corte di giustizia», Rivista di diritto internazionale, v. 89, n. 4, 2006, páginas 948-977 y A. Stadler, «From the Brussels Convention to regulation 44/2001: cornerstones of a European law of civil procedure», Common Market Law Review, v. 42, n. 6 , December, 2005, páginas 1637-1661.

${ }_{12}$ Cabe citar en este punto a F. P. Mansi, «Il giudice italiano e le controversie europee: dalla Convenzione di Bruxelles del 1968 alla Convenzione di Lugano del 1988 ed al Regolamento (CE) n. 44/2001", Milano: Giuffrè, 2004, C. Bonaduce, "L'interpretazione della Convenzione di Bruxelles del 1968 alla luce del Regolamento $\mathbf{n}$. 44/2001 nelle pronunce della Corte di giustizia", Rivista di diritto internazionale, v. 86, n. 3, 2003, página 746-758, F. Salerno, "Giurisdizione ed efficacia delle decisioni straniere nel regolamento (CE) n. 44/2001: la revisione della Convenzione di Bruxelles del 1968»; 2. ed, Padova: CEDAM, 2003, Siani, V., «Il regolamento CE n. 44/2001 sulla competenza giurisdizionale e sull'esecuzione delle sentenze. Parte prima, La cooperazione giudiziaria in materia civile e commerciale: dalla Convenzione di Bruxelles al regolamento (CE) n. 44/2001", Diritto comunitario e degli scambi internazionali, anno 42, n. 3, luglio-settembre, 2003, páginas 451-534, Carbone, S. M., Il nuovo spazio giudiziario europeo dalla Convenzione di Bruxelles al Regolamento CE 44/2001, 4. ed., Torino: Giappichelli, 2002, A. Nuyts, «La communautarisation de la convention de Bruxelles: le règlement 44/2001 sur la compétence judiciaire et l'effet des décisions en matière civile et commerciale", Journal des tribunaux, v. 120, n. 6035, 2001, páginas 913-922, H. Tagaras, "La révision et communautarisation de la Convention de Bruxelles par le règlement 44/2001", Cahiers de droit européen, v. 39, n. 3-4, 2003, páginas 399-432. 
lada a la responsabilidad parental. Se trata pues, de una regulación sectorial, eficaz y necesaria en su ámbito de aplicación, pero que no emana de un principio de protección integral del menor, que sin embargo sí se vislumbra en el Reglamento 2201/2003.

El más directo de los antecedentes legislativos del actual Reglamento fue el Reglamento del Consejo de la UE n. ${ }^{\circ} 1347 / 2000$ o Reglamento Bruselas II relativo a la competencia, el reconocimiento y la ejecución de resoluciones judiciales en materia matrimonial y de responsabilidad parental sobre los hijos comunes ${ }^{13}$. Este Reglamento fue aplicado desde su entrada en vigor el 1 de marzo de 2001, hasta el comienzo de la andadura del actual Reglamento.

Las principales innovaciones del Reglamento 2201/2003 o Bruselas II bis ${ }^{14}$ en relación con el 1347/2000 o Bruselas II, se centran en la superior ambición de aquél por regular el mayor tipo posible de relaciones paterno-filiales, incluyendo ahora tanto las matrimoniales como las no matrimoniales, así como todo tipo de vinculación con los menores, también la de las personas jurídicas o las existentes con otros parientes que no sean los progenitores ${ }^{15}$. Es decir, se trata de ex-

13 Véase A. Bonomi, «Il regolamento comunitario sulla competenza e sul riconoscimento in materia matrimoniale e di potestà dei genitori", Rivista di diritto internazionale, v. 84, n. 2, 2001, páginas 298-346, H. Gaudemet-Tallon, "Le Règlement $\mathrm{n}^{\circ}$ 1347/2000 du Conseil du 29 mai 2000: "compétence, reconnaissance et exécution des décisions en matière matrimoniale et en matière de responsabilité parentale des enfant communs", Journal du droit international, v. 128, n. 2, 2001, páginas 381-445 y M. A. Sánchez Jiménez, «La libre circulación de decisiones de divorcio en la U.E. tras la entrada en vigor del reglamento n 1347/2000", Anales de derecho, n. 18, 2000, páginas 157-204.

${ }^{14}$ Un análisis general sobre el reglamento puede encontrarse en F. Uccella, Il diritto comunitario sulle decisioni in materia matrimoniale e di responsabilità genitoriale: regolamento (CE) n. 2201/2003 del 27 novembre 2003, relativo alla competenza, al riconoscimento e all'esecuzione delle decisioni in materia matrimoniale e in materia di responsabilità genitoriale, Salerno: Edisud, 2005 y A. di Lieto, «Il regolamento n. 2201/2003 relativo alla competenza, al riconoscimento e all'esecuzione delle decisioni in materia matrimoniale e in materia di responsabilità genitoriale", Diritto comunitario e degli scambi internazionali, anno 43, n. 1, gennaio-marzo, 2004, páginas 117-137.

15 Véase F. F. Garau Sobrino, «El ámbito de aplicación del reglamento 1347/2000 en materia matrimonial y de responsabilidad parental sobre los hijos comunes», El derecho de familia ante el siglo XXI: aspectos internacionales, coord. por Esperanza Castellanos Ruiz, Alfonso Luis Calvo Caravaca, 2004, páginas 399-410. Sobre el derecho del menor a mantener relaciones con ambos progenitores, M. P. Diago Diago, «El derecho de los hijos a mantener relaciones personales con ambos progenitores. A propósito de la propuesta de Reglamento del Consejo relativo a la competencia, el reconocimiento y la ejecución de resoluciones judiciales en materia matrimonial y de responsabilidad parental y su extensión a la sustracción de menores», Cursos de derechos humanos de Donostia-San Sebastián, Vol. 4, 1999, páginas 205-220. 
tender la regulación del Reglamento a un ámbito más extenso de relaciones con el menor, que supere el estricto círculo paterno-filial e incluso las relaciones consanguíneas, para alcanzar, por ejemplo, las relaciones por afinidad. El cambio que implica el nuevo Reglamento se debe a que éste centra su atención en los menores y su protección, mientras que el Reglamento derogado tenía a los padres como eje de su regulación ${ }^{16}$. La trascendencia de esta reflexión, en mi opinión, es que no estamos ante una mera mejora legislativa, sino ante un instrumento jurídico que emana de la consolidación, cada vez más evidente, del principio del interés superior del menor, primando su beneficio como valor fundamental.

En efecto, el principio esencial que rige toda la regulación comunitaria es el del beneficio del menor como interés superior, que ha de prevalecer sobre cualquier otro aunque sea legítimo. Se trata de dejar de centrar la atención en los cónyuges y en los padres para poner todo el énfasis en la protección de los menores que se ven afectados porque se han adoptado resoluciones judiciales que les vinculan. Un ejemplo de ello, es el principio de la audiencia al menor, desarrollado en el Reglamento y que desempeña un papel importante por la sustantividad propia que se confiere a la actuación procesal del mismo en concordancia con la significación que se da a los intereses que le son privativos, sin que con ello se pretendan modificar los procedimientos nacionales en la materia. Otra manifestación del principio del interés superior del menor, se encuentra, en mi opinión, en el criterio de la proximidad a la residencia habitual del menor al que atiende el Reglamento para fijar los foros competenciales, lo que significa que han de ser los órganos jurisdiccionales del Estado miembro en el cual aquél tiene su residencia habitual, los que deben, en primer lugar, ostentar la competencia, excepto en ciertos casos de cambio de residencia del menor o en el supuesto de que exista un acuerdo contrario entre los titulares de la responsabilidad parental. Un último exponente del principio puede encontrarse en la búsqueda de la igualdad de todos los hijos, por lo que la aplicación del Reglamento se extiende a todas las resoluciones en materia de responsabilidad parental, con independencia de que estén vinculadas o no a un procedimiento matrimonial.

${ }^{16}$ La modificación operada por el Reglamento (CE) n. ${ }^{\circ} 2116 / 2004$ del Consejo de 2 de diciembre de $2004^{16}$, ha incidido en el Reglamento 2201/2003 en lo referente a los Tratados suscritos con la Santa Sede a fin de incorporar a ellos el referente a Malta que se integro en la Unión Europea el 1 de mayo de 2004. 
En segundo término y como indica Cobo Sáenz ${ }^{17}$ la regulación del Reglamento se asienta en dos ejes, que son, por una parte, el reconocimiento o valor directo de las resoluciones extranjeras sin necesidad de exequátur si no existe oposición y por otra parte, el objetivo de alcanzar un procedimiento homogéneo de ejecución, en cuanto a órganos internos, recursos y plazos. Todo ello es una manifestación del principio de confianza mutua entre Estados miembros que exige que los motivos de una denegación de reconocimiento se limiten al mínimo necesario. El Reglamento 2201/03 busca pues, la homogeneización a través de la armonización procesal ${ }^{18}$ y ésta se basa a su vez, en los principios de cooperación y de confianza mutua. Pero no puede desligarse del movimiento general de armonización de las instituciones de derecho privado en la regulación de sus contenidos materiales, que resulta necesaria para la consecución del objetivo comunitario de creación de un espacio de libertad, seguridad y justicia ${ }^{19}$.

En este sentido, puede señalarse también como logro del Reglamento, en la línea de la cooperación pretendida, el haber buscado asentar una terminología uniforme con el propósito de evitar, en lo posible, conflictos jurídicos derivados de interpretaciones divergentes con respecto a conceptos susceptibles de interpretaciones diversas. Así se han intentado concertar los conceptos de órgano jurisdiccional, Juez, resolución judicial, Estado miembro de origen, responsabilidad parental, derecho de custodia y derecho de visita.

Siguiendo a Ortuño Muñoz ${ }^{20}$, con respecto al concepto de órgano jurisdiccional a los efectos del Reglamento ha de entenderse éste referido a todas las entidades de los Estados miembros, sean o no judiciales, que tengan atribuida según su legislación interna, competencia sobre las materias a que se refiere el mismo. Resulta especialmente destacable la adopción de este concepto amplio, puesto que en el ám-

17 J.F. Cobo Sáenz, op. cit., página 52.

${ }^{18}$ Lo que no constituye una novedad de este Reglamento. Véase P. Franzina, «Il coordinamento fra «lex fori» e norme uniformi nell'accertamento del titolo di giurisdizione secondo il regolamento (CE) N. 44/2001", Rivista di diritto internazionale, v. 87 , n. 2, 2004, páginas 345-392.

19 Véase M. L. Puerto Mendoza, «La libre circulación de resoluciones judiciales sobre responsabilidad parental dentro de la Unión Europea», La Ley: Revista jurídica española de doctrina, jurisprudencia y bibliografía, ISSN 0211-2744, N. ${ }^{\circ} 5,2002$, páginas 1692-1699.

${ }^{20}$ Ortuño Muñoz, $P$., «Competencia judicial internacional y reconocimiento de decisiones en materia de protección de menores. Aplicación conjunta de distintos instrumentos internacionales. Reglamento (CE) 2201/2003", Cooperación judicial en materia de familia y relaciones parentales en la UE, Madrid: CGPJ, 2006, página 161 y siguientes. 
bito comunitario conviven sistemas de muy diversa índole, en los que se atribuye la competencia de adoptar decisiones sobre responsabilidad parental, tanto a los Tribunales de justicia, como a órganos administrativos. Como dice el referido autor, el dotar de equivalencia a estas entidades puede dar lugar a que una decisión adoptada por una entidad municipal en un Estado haya de ser ejecutada por un órgano jurisdiccional, en el sentido propio del término, en otro y a la inversa.

Por "Juez» habrá de entenderse cualquier autoridad que ejerza las funciones de órgano jurisdiccional en el sentido anteriormente expuesto. Habrá de estarse por lo tanto, a la legislación interna de cada Estado para determinar que ha de entenderse por tal y quién ha de desempeñar las funciones exigidas por el Reglamento para el reconocimiento de las resoluciones, como por ejemplo, la audiencia a las partes o al menor.

En la misma línea, como «resolución judicial» tendrá cabida cualquier decisión, sea cual fuere su forma, que contenga el fallo de la autoridad competente en la materia, según la legislación interna.

Ha de tenerse en cuenta que el principio de confianza mutua excluye cualquier tipo de control indirecto de la competencia del órgano que adoptó la decisión, o de revisión en cuanto al fondo de la misma, tal como disponen los artículos 24 y 26 del Reglamento, ya que tales aspectos vienen garantizados por el certificado previsto en el artículo 39. Destaca igualmente la novedosa la asimilación que el Reglamento realiza entre los documentos públicos y los acuerdos entre las partes, con la condición de que sean ejecutivos en el Estado miembro en el que se otorgaron o se suscribieron, lo que implica, por ejemplo, que en España carezca de eficacia un acuerdo privado suscrito entre españoles y en territorio nacional que no haya sido homologado judicialmente, mientras que debería ser reconocido el mismo acuerdo si ha sido suscrito en Finlandia, pues la ley interna de este país sí lo permite» ${ }^{21}$.

Como Estado miembro de origen ha de entenderse el de la decisión o resolución que se pretende reconocer o ejecutar en el «Estado miembro de ejecución». El Reglamento 2201 se aplica en todos los Estados de la UE con excepción de Dinamarca, pues el Reino Unido e Irlanda manifestaron, de conformidad al artículo 3 del Protocolo sobre su respectiva posición, anejo al TUE y al TCE, su intención de participar en la adopción y aplicación del mismo.

21 Ortuño Muñoz, op. cit., página 163. 
Con respecto a los conceptos de responsabilidad parental, derecho de custodia y derecho de visita, de los que, posteriormente, se hará una exposición más extensa, cabe adelantar aquí que resulta de esencial importancia que se hayan consensuado, no sólo por la eficacia con que este consenso dota a las actuaciones en beneficio de los menores y demás afectados por la relación parental, sino porque con el establecimiento de estos conceptos básicos se teje un entramado institucional uniforme en materia civil entre los Estados de la Unión, lo que trasciende a los meros actos de cooperación para crear unos principios informadores compartidos que pasan a formar parte del acervo comunitario, impulsando, en consecuencia, el desarrollo de una cultura jurídica común volcada cada vez mas en aspectos esenciales de la vida privada del ciudadano europeo.

Ha de tenerse en cuenta, por otra parte, que la interpretación última de los conceptos contenidos en el Reglamento, así como de cualquiera de sus disposiciones, habrá de encomendarse al TJCE en sede prejudicial de conformidad a los artículos 68 y 234 del TCE.

\section{III. ÁMBITO MATERIAL DE APLICACIÓN}

Resulta especialmente destacable la relevancia de las materias contenidas en el Reglamento 2201/2003, en materia de responsabilidad parental. Diversas circunstancias sociales y políticas han justificado la necesidad de la regulación de estas cuestiones en un Reglamento comunitario, es decir, un instrumento jurídico obligatorio y directamente aplicable en todos los Estados miembros con la excepción de Dinamarca. De entre estas circunstancias sobresale, como indica López Vicente ${ }^{22}$, el creciente aumento del número de traslados ilícitos de menores, la evolución del derecho de familia en relación con el progresivo número de crisis familiares, matrimoniales y no matrimoniales, las dificultades para el reconocimiento y la ejecución de resoluciones judiciales dictadas en materia de responsabilidad parental y matrimonial y finalmente, la gran sensibilidad social que rodea a estas materias.

La tendencia a la armonización legislativa general en el ámbito comunitario, no podía dejar de tener trascendencia en este ámbito,

${ }^{22}$ López Vicente, P., «El Reglamento (CE) 2201/2003: el alcance del reconocimiento mutuo de las Decisiones sobre el Derecho de visita y secuestro de menores", Cooperación judicial en materia de familia y relaciones parentales en la UE, Madrid: CGPJ, 2006, página 106. 
donde puede ofrecer tantos elementos ventajosos a una sociedad europea que reclama soluciones para facilitar la efectividad de los pronunciamientos judiciales dictados para la normalización de la situación de los menores. Este requerimiento social se ha visto incrementado por los insuficientes resultados obtenidos mediante la aplicación del Convenio de La Haya sobre Sustracción Internacional de Menores de 1980.

El Reglamento 2201/2003, como se expuso anteriormente, no es una norma de derecho material sobre la responsabilidad parental, sino un instrumento de derecho procesal civil internacional en materia de competencia y reconocimiento de resoluciones, que busca allanar la solución de conflictos de competencia en el reconocimiento y ejecución de decisiones y la cooperación de las autoridades nacionales de los Estados miembros. Es decir, lo que persigue el Reglamento es la armonización y la cooperación entre los Estados miembros en la aplicación de sus respectivas leyes sobre responsabilidad parental y crisis matrimoniales, cuya idiosincrasia se respeta y se mantiene, y ello, como dice Ortuño Muñoz $^{23}$ "en virtud de una especie de compromiso pragmático basado en la confianza mutua, del que son expresión: a) la ausencia de reglas de conflictos de leyes (diferencia notable con el Convenio de la Haya de 1996 que, en esta materia, permanecerá en vigor), b) la regla respecto al reconocimiento de las resoluciones recogida en el artículo 26, en virtud del cual las resoluciones no podrán en ningún caso ser objeto de una revisión en cuanto al fondo y c) las tasadas causas de denegación del reconocimiento que recoge el artículo 23, prácticamente todas referidas a cuestiones procesales, con excepción de la cláusula de orden público del Estado requerido, matizado con los términos 'manifestamente contrario' y la apelación al interés superior del menor».

Si bien esta aproximación de las normas procesales es el objetivo fundamental del Reglamento, puesto que se enmarca en el ámbito de la cooperación, ello no significa que no exista el objetivo comunitario de alcanzar el establecimiento de unas instituciones jurídicas uniformes, en el ámbito material o de fondo, con fundamento en una tradición jurídica compartida. En este sentido, es decir, en el aspecto propiamente material de la responsabilidad parental, se está configurando esta institución como un conjunto de derechos, deberes y valores, regidos por el principio del interés superior del menor, que tiene trascendencia público-internacional, puesto que deriva de di-

${ }^{23}$ Op. cit, página 156. 
versas fuentes de este carácter, como los Tratados europeos incluido el Tratado constitucional, la Declaración Universal de los Derechos del niño, la Carta Europea de Derechos Humanos y los demás Convenios internacionales que inciden en la materia. De estas fuentes emana igualmente un principio común de orden público internacional consistente en que el Estado debe garantizar a todos los menores que se hallen en su territorio, un elenco de derechos básicos relativos a la salud, a la integridad física y moral, a la educación, a mantener relación con sus progenitores y en general, los derechos fundamentales de la persona. Los menores se hallan obligados por su parte al aprendizaje y aceptación de las normas esenciales de la comunidad donde se hallen, que vendrán determinadas por la legislación de cada Estado ${ }^{24}$.

Por todo ello, primeramente y como paso previo a precisar el ámbito del Reglamento 2201, ha de determinarse cual es el contenido y campo propio del derecho civil y mercantil en el marco del derecho comunitario. Son materias incluidas ${ }^{25}$ desde esta perspectiva general en el ámbito del derecho civil comunitario, las obligaciones alimenticias vinculadas a la responsabilidad parental, los efectos patrimoniales del matrimonio y sus crisis, los deberes resarcitorios imputables a la responsabilidad extracontractual de las Administraciones públicas y las resoluciones en materia de responsabilidad civil dictadas por órganos de la jurisdicción penal. Por otra parte, son materias excluidas: el estado y la capacidad de las personas físicas, los regímenes matrimoniales, los testamentos y las sucesiones.

Centrándonos ya en el Reglamento 2201, a pesar de la casuística regulación de inclusiones y exclusiones que realiza, respecto a su ámbito material de aplicación pueden suscitarse dudas interpretativas, para las que resultará de utilidad el Convenio de La Haya de 19 de octubre de 1996. Ortuño Muñoz ${ }^{26}$ señala como ejemplos de estas posibles interrogantes interpretativas las referentes a determinadas materias administrativas tendentes a la protección del niño o a las medidas adoptadas en causas penales, tanto cuando los infractores sean los menores como cuando lo sean los que ejerzan la responsabilidad parental, por ejemplo, en los casos de violencia doméstica. Según Caro Gándara ${ }^{27}$, el que algunas de las medidas de protección de

${ }^{24}$ En España habrá que acudir al Código Civil y a la legislación autonómica.

25 Véase Cobo Sáenz, op. cit., página 59.

26 Op. cit., página 165.

27 Caro Gándara, R., «Nuevos desafios comunitarios en materia matrimonial y de responsabilidad parental en las relaciones jurídicas transfronterizas», (Competencia 
los menores presenten perfiles públicos y privados, puede dar lugar también a problemas interpretativos, teniendo en cuenta los casos concretos excluidos en el considerando 10 del Reglamento, es decir, seguridad social, medidas de derecho público en materia de educación y salud y resoluciones relativas a derecho de asilo e inmigración, así como la cuestión de definir el acogimiento preadoptivo, puesto que el acogimiento familiar aparece incluido en el ámbito de aplicación del Reglamento y sin embargo, están excluidas las medidas que preparan la adopción, según el artículo 1.3.b ${ }^{28}$.

Si bien se trata de cuestiones que se regulan en el marco del derecho civil o privado en la generalidad de los ordenamientos jurídicos de los Estados miembros, es también comúnmente reconocido que el Estado ha de intervenir en la vigilancia de la responsabilidad parental, aunque ello represente una injerencia en el ámbito privado de las familias. Los aspectos que han de respetarse en esta intromisión de las instituciones públicas en aras de la inspección del ejercicio de la responsabilidad parental son las contenidas en la STEDH de 24-31988 dictada en el caso Olson vs. Suecia (n . $\left.{ }^{\circ} 10465 / 83\right)$, que se concretan en que:

- toda actuación pública en esta materia ha de estar sujeta al principio de legalidad,

- ha de resultar necesaria ${ }^{29}$,

- su finalidad ha de ser legítima,

- las medidas que se adopten han de ser proporcionales al riesgo que puedan causar,

judicial internacional, reconocimiento y ejecución de resoluciones en materia de familia y sustracción internacional de menores a la luz del Reglamento 2201/2003)", Estudios Jurídicos (2004) página 4695-4731. Disponible en <http:www.cej.justicia.es $/ p d f / p u b l i c a c i o n e s / s e c r e t a r i o s \_j u d i c i a l e s / S E C J U D 11 . p d f>$, página 4704.

${ }_{28}$ Esta misma autora cita a G. Esteban de la Rosa, El acogimiento internacional de menores. Régimen jurídico, Granada: Comares, 2000, página 49, en el sentido de considerar que el Reglamento 2201/2003 se inspira en el Convenio de La Haya de 1996 y que éste también incluye entre las medidas protectoras el acogimiento preadoptivo, mientras que el Informe explicativo del Convenio elaborado por P. Lagarde, parece excluirlo en su artículo 4 b).

${ }_{29}$ Según Ortuño Muñoz, op. cit., página 158, «la necesidad y finalidad legítima de las medidas que los sistemas legales prevén supone que, aun cuando pertenezcan a la esfera de la protección social de carácter administrativo en desarrollo de las políticas de bienestar social, han de estar inspiradas, en todo caso, por el principio del interés del menor y sujetas a control jurisdiccional desde la perspectiva de los derechos fundamentales de la persona». 
- ha de garantizarse la imparcialidad, que se dará cuando se hayan conocido todos los puntos de vista.

Desde el punto de vista subjetivo, habrá que determinar que se entiende por menor a los efectos del Reglamento 2201. No se especifica, cual es el límite de edad del niño sujeto a la responsabilidad parental, para lo que podrá acudirse al Convenio de La Haya de 1996 que señala el límite de la minoría de edad en 18 años. Quedan también fuera del Reglamento los incapaces que hayan alcanzado la mayoría de edad, pero sobre los que se ejerza la responsabilidad parental para su tutela. No se hace excepción alguna con respecto a los menores susceptibles de emancipación según la legislación nacional, en lo que se refiere a su capacidad parcial para determinados actos.

En lo que aquí interesa, es decir, en materia de responsabilidad parental, el Reglamento 2201/2003 se aplica a todas las resoluciones respecto de los hijos menores de edad, con independencia, como se decía anteriormente, de que entre sus padres exista o no vínculo matrimonial, - con lo que se trata de garantizar la igualdad de todos los hijos-, cuando residan habitualmente en un Estado miembro en el momento en que se presente el asunto ante el órgano jurisdiccional. Con ello se trata de poner remedio a las "deficiencias» observadas en el Reglamento 1347/00, que había recibido bastantes críticas respecto al ámbito de aplicación personal sobre el que recaía, fundamentalmente por no contemplar la situación de los hijos no comunes del matrimonio o de los hijos comunes habidos fuera del vínculo matrimonial, así como por la carencia de soluciones que daba a los conflictos sobre el derecho de visita ${ }^{30}$. El nuevo Reglamento se aplica tanto a los menores nacionales del país donde tienen su residencia, como a aquellos otros menores que tienen vínculos suficientemente profundos con el territorio de uno de los Estados miembros.

Se incluyen por tanto, todas las decisiones referentes al ámbito familiar y de filiación excluidas del Reglamento 44/01 o Bruselas I que es el que trata de la materia civil y mercantil en general. Uno de los aspectos positivos del Reglamento y que pone de manifiesto también el propósito de constituir una regulación lo más extensa posible en la materia, es que el término decisión no se refiere sólo a las decisiones judiciales, sino también, como se expuso más arriba, a las que hayan adoptado autoridades administrativas, tratando con ello de coordinar

${ }^{30}$ Véase E. Rubio Torrano, «Conflictos matrimoniales y responsabilidad parental: Nuevo Reglamento comunitario», Aranzadi Civil, num. 21/2003 Parte Tribunal Editorial Aranzadi, 2004. 
las distintas variedades que puedan ofrecer los ordenamientos jurídicos nacionales ${ }^{31}$. Sólo se excluyen de su ámbito de aplicación los procedimientos de naturaleza religiosa. Por otra parte, esta profundidad de la regulación se manifiesta también en la forma en que el artículo 2.4 independiza el concepto de resolución judicial de su denominación, incluyendo, no obstante, los términos sentencia y auto ${ }^{32}$.

Concretando más las materias reguladas por el Reglamento y específicamente en materia de responsabilidad parental, éstas son las siguientes: la atribución, el ejercicio, la delegación, la restricción o la finalización de la responsabilidad parental que incluyen el derecho de custodia y de visita, la tutela, curatela y otras instituciones análogas, la designación y las funciones de toda persona u organismo encargado de ocuparse de la persona o de los bienes de menor, de representarlo o de prestarle asistencia, el acogimiento del menor en una familia o en un establecimiento y las medidas de protección del menor ligadas a la administración, conservación o disposición de sus bienes. El Reglamento se aplica a las materias expuestas, con independencia de que éstas, en el ámbito del derecho interno, sean consideradas de naturaleza civil o, por ejemplo, se considere que el acogimiento de un menor desamparado pertenece al ámbito del «Derecho público».

Ha de tenerse en cuenta que esta enumeración de contenidos es enunciativa y no exhaustiva. Por ello autores como Puig Blanes ${ }^{33}$ consideran que podrían incluirse dentro del ámbito del Reglamento, las medidas que posean consecuencias patrimoniales de carácter protector, como por ejemplo, las autorizaciones judiciales de enajenación de bienes de menores dictadas en procesos de jurisdicción voluntaria ${ }^{34}$.

31 Como ejemplo se señala por Puig Blanes, op. cit., página 27, el caso de Finlandia en el que las cuestiones referentes a la guarda, residencia y visita de menores pueden solucionarse al margen de un procedimiento judicial mediante un acuerdo que luego aprueba el Departamento de Asuntos Sociales local.

${ }_{32}$ Como precedente puede citarse el artículo 32 del Reglamento 44/2001 según el cual el término resolución incluye «cualquier decisión adoptada por un tribunal de un Estado miembro, con independencia de la denominación que recibiere, tal como auto, sentencia, providencia o mandamiento de ejecución, así como el acto por el cual el Secretario Judicial liquidare las costas del proceso». Es independiente de la nacionalidad o el domicilio de los litigantes y no es preciso que se haya adoptado en virtud de los foros de competencia internacional fijados en el Reglamento. Según los artículos 57 y 58 son también ejecutables los documentos públicos con fuerza ejecutiva y las transacciones judiciales.

${ }_{33}$ Op. cit., página 31.

${ }^{34}$ Las medidas que no tuvieran tal condición protectora se regularían por el régimen del Reglamento 44/2001 (Bruselas I). 
Para terminar de delimitar el ámbito material de aplicación han de exponerse también los supuestos excluidos que son: la determinación e impugnación de la filiación, las resoluciones sobre adopción y medidas que la preparan, así como su anulación y revocación, la determinación del nombre y de los apellidos, la emancipación, los alimentos $^{35}$, los fideicomisos y sucesiones y las medidas adoptadas como consecuencia de infracciones de carácter penal cometidas por los menores ${ }^{36}$. Estas materias están reguladas por el Reglamento Bruselas I, si entran dentro de su ámbito de aplicación o por los Convenios bilaterales que puedan existir entre los Estados afectados, en defecto de aquél. En el caso de que tampoco existieran éstos últimos, operaría el principio de reciprocidad ${ }^{37}$.

La exclusión de la determinación e impugnación de la filiación se basa en que se considera una materia distinta de la atribución de la responsabilidad parental, regulándose por el derecho nacional de cada Estado, al igual que cualquier otro derecho relativo a la persona, sin perjuicio de que en materia probatoria pueda ser utilizado el Reglamento 1206/2001.

Con respecto a las medidas sobre adopción y actos que la preparan como acogimientos preadoptivos o régimen de obtención de consentimientos y asentimientos, así como las medidas de anulación o revocación, deberán regularse en su vertiente trasnacional fuera del ámbito comunitario, por el Convenio de La Haya de 1993 entre los Estados que lo hayan ratificado. La exclusión de la emancipación resulta comprensible puesto que su presupuesto esencial es la autonomía del menor y por consiguiente, la inecesariedad de su protección.

${ }^{35}$ Con respecto a los alimentos, el considerando $n .^{\circ} 11$ del Reglamento establece que «las obligaciones alimentarias, al estar ya reguladas en el Reglamento (CE) n. ${ }^{\circ}$ 44/2001 (LCEur/2001/84), están excluidas del ámbito de aplicación del presente Reglamento. Los órganos jurisdiccionales competentes en virtud del presente Reglamento tendrán generalmente competencia para pronunciarse en materia de obligaciones alimentarias en aplicación de lo dispuesto en el apartado 2 del artículo 5 del Reglamento (CE) n. ${ }^{\circ} 44 / 2001$ ".

${ }_{36}$ Como se establece en el considerando décimo del Reglamento: «no se pretende que el presente Reglamento se aplique a asuntos tales como los relativos a la seguridad social, a las medidas de Derecho público de carácter general en materia de educación y salud, ni a las resoluciones relativas al derecho de asilo y a la inmigración. No se aplica, por lo demás, al establecimiento de la filiación, que es una cuestión distinta de la atribución de la responsabilidad parental, ni a las demás cuestiones ligadas al estado de las personas. Tampoco se aplica a las medidas adoptadas a consecuencia de infracciones penales cometidas por menores».

37 En el caso de que, como es lo usual, una resolución contenga pronunciamientos de diversa índole, se aplicarán los correspondientes Reglamentos para la ejecución de cada uno de ellos. 
Por lo que respecta a la esfera patrimonial de los menores, el Reglamento 2201/2003 sólo se aplica a las medidas de protección del menor, o lo que es lo mismo, a la designación y funciones de la persona $\mathrm{u}$ organismo encargado de administrar los bienes del menor, de representarlo y de prestarle asistencia y a las medidas relativas a la administración, conservación o disposición de sus bienes. Cuando se trate de medidas referidas al patrimonio del menor pero que no contengan este elemento de guarda y protección del mismo, quedan fuera de su ámbito, rigiéndose por el Reglamento Bruselas $I^{38}$. La determinación de cuando una específica medida esta vinculada o no con su protección, es una decisión judicial a adoptar en cada caso concreto.

Los alimentos quedan excluidos por entenderse que su objeto pertenece al ámbito del Reglamento CE 44/2001, si bien lo que va a producirse con frecuencia es una concurrencia en la tramitación de ambas pretensiones, es decir, una acumulación del reconocimiento de las resoluciones relativas a la responsabilidad parental y de las relativas a los alimentos ante los mismos órganos jurisdiccionales, aunque las normas que haya que aplicar para resolver ambos aspectos sean diferentes.

También se excluyen los asuntos relativos a la seguridad social, medidas generales sobre salud o educación cuando no se trate de medidas concretas o individualizadas y derecho de asilo e inmigración, sin perjuicio de la protección que haya de prestarse a los niños. No obstante, recuerda Ortuño Muñoz $^{39}$ que las exclusiones, en la aplicación del Reglamento deberán interpretarse de forma flexible en aras de la eficacia y pone el ejemplo de que de nada serviría el reconocimiento de una resolución sobre el régimen de visitas o administración de bienes de un progenitor no residente comunitario, al que no se le facilitara, al mismo tiempo, la circulación y estancia en el Estado de residencia del menor, en alguna de sus modalidades.

El ámbito de aplicación del Reglamento se extiende también a las costas generadas y a la ejecución de cualquier resolución relativa a las mismas, exceptuándose el supuesto del reconocimiento y ejecución de resoluciones sobre cumplimiento del derecho de visitas y restitución del menor que se entiende ha de ser gratuito (artículo 49).

38 Las medidas derivadas de la comisión de una infracción penal por el menor no entran en la órbita del Reglamento, aunque puedan estar vinculadas a su protección patrimonial.

${ }^{39}$ Op. cit., página 168 . 
Habida cuenta de que se viene desarrollando como alternativa a la solución judicial de las crisis matrimoniales y de sus efectos, la mediación familiar, tanto a nivel interno como en el ámbito internacional, cabe por último plantearse si el Reglamento 2201/2003 habría de tenerse en cuenta en estos casos. No parece que pueda mantenerse su aplicación, puesto que claramente se refiere el Reglamento a los supuestos de resoluciones adoptadas por órganos jurisdiccionales, aunque se entiendan los mismos en sentido amplio. Como indica Cordero Álvare $\mathrm{z}^{40}$, faltando una normativa expresa en el sistema de derecho internacional privado, su funcionamiento en supuestos transfronterizos parte de la autonomía de la voluntad de las partes, si bien distinguiéndose entre el régimen del contrato de mediación familiar internacional y el acuerdo de mediación familiar internacional. Mediante el primero se vinculan las partes y el mediador y se regula el funcionamiento de la mediación. Tratándose de un contrato, está comprendido dentro del ámbito de las obligaciones convencionales, pudiendo aplicarse por ello el régimen general del Convenio de Roma de 1980 sobre ley aplicable a las obligaciones contractuales, vigente para España desde el año 1993. Por su parte, el acuerdo de mediación familiar internacional incluiría los pactos entre las partes sobre las distintas cuestiones relacionadas con la disolución de la relación matrimonial, obtenidos tras la mediación. Tratándose de un negocio jurídico de derecho de familia quedaría excluido de las normas del Convenio de Roma (artículo 1.2.b), defendiéndose por Cordero Álvarez ${ }^{41}$ tanto la aplicación del artículo 9.2, por analogía con el régimen de pactos de la separación de hecho y su adscripción al régimen de relaciones personales y patrimoniales entre los cónyuges, como del artículo 107 del CC, buscando una identidad con las soluciones judiciales de las crisis matrimoniales.

\section{CONCEPTOS DEFINIDOS EN EL REGLAMENTO DE ESPECIAL SIGNIFICACIÓN}

\section{CONCEPTO DE RESPONSABILIDAD PARENTAL}

Se exponía al principio que uno de los principales logros del Reglamento es la armonización terminológica, aspecto que incide es-

${ }^{40}$ Cordero Álvarez, C. I., «Crisis matrimoniales y responsabilidad parental dentro y fuera de la Unión Europea: el Código de Familia Comunitario», Anuario jurídico y económico escurialense, N. ${ }^{\circ} 39,2006$, páginas 215-258, página 258.

41 Op. cit., página 258. 
pecialmente en la determinación de su ámbito material. La responsabilidad parental, como institución jurídica, es el concepto moderno de una relación social típica, que se ha ido constituyendo históricamente $^{42}$. Se basa en un vínculo interpersonal de carácter natural, anterior a su formulación por el derecho, existente en todas las sociedades, que se ha trasladado a la esfera de lo jurídico con una gran dependencia de la moral, de la ideología, de la religión, de la economía y de los principios éticos existentes en cada momento histórico. Esta institución cuyos fundamentos jurídicos se encuentran, en nuestro entorno cultural, en el derecho romano, y que ha mantenido sus aspectos sustanciales hasta nuestros días, se halla, no obstante, expuesta a una evolución motivada por diversos factores, tales como la igualación de la mujer con el hombre en el sistema de la relación con los hijos, -lo que desvirtúa el término de "patria potestad"-, la implantación del divorcio que ocasiona la obligatoriedad de regular y compartir las responsabilidades y derechos derivados de la institución en cada caso concreto, la irrupción de nuevas formas de familia, el reforzamiento del carácter asistencial de las funciones que le son propias con la consiguiente generación de funciones suprafamiliares que son compartidas con la comunidad ${ }^{43}$ y finalmente, la consolidación del principio del «interés del menor», de carácter jurídico y universal, siendo el criterio preferente a tener en cuenta en la toma de decisiones.

Se señalan también como factores de cambio, circunstancias sociológicas como la necesidad de buscar nuevos modelos de familia para el cuidado de los menores, y en general, los movimientos de población transnacional cada vez más intensos, que en el ámbito europeo se intentan enmarcar en un entorno jurídico, seguro y consolidado, para alcanzar el objetivo comunitario del espacio de libertad, seguridad y justicia, en el que se garantiza la libre circulación de personas.

El artículo 1.2 del Convenio de La Haya de 19 de octubre de 1996 define la responsabilidad parental del siguiente modo: «comprende la autoridad parental o todo otro referente de autoridad análogo que de-

42 Ortuño Muñoz, op. cit., página 153. Este mismo autor se remonta a las mitologías egipcia, griega y romana para encontrar la relación entre este vínculo y lo sagrado, con gran carga de trascendencia en todas las religiones.

${ }_{43}^{4}$ «En una tendencia de progresiva secularización de la materia, que ha pasado a ostentar un papel de vigilancia del correcto cumplimiento de la responsabilidad parental, con facultades de suspensión, supresión o condicionamiento de las funciones paternas y maternas mediante un amplio sistema de medidas protectoras que, en muchos casos, son de suplencia temporal o definitiva" Ibidem. 
termine los derechos, los poderes y las obligaciones de los padres, de un tutor o de otro representante legal que tenga a su cuidado la persona o bienes del niño».

Una de las críticas que recayeron sobre el Reglamento 1347/2000 fue la falta de delimitación del alcance de la expresión "responsabilidad parental». Haciéndose eco de estas observaciones es por lo que el Reglamento 2001/03 define ésta en su artículo 2.7. El artículo 2.7 del Reglamento 2201/2003 ajusta conceptualmente la definición del Convenio de La Haya, entendiendo que la responsabilidad parental consiste en «los derechos y obligaciones conferidos a una persona física o jurídica en virtud de una resolución judicial, por ministerio de la ley o por un acuerdo con efectos jurídicos, en relación con la persona o los bienes de un menor. El término incluye, en particular, los derechos de custodia y visita".

Con fundamento en lo anterior, los puntales del concepto de responsabilidad parental son: la persona del niño en todo lo referente a su alimentación, educación y salud, su patrimonio, su representación, su custodia, el derecho de relación con los progenitores que no tengan la custodia o no convivan habitualmente con el menor, así como las instituciones supletorias clásicas del acogimiento, la tutela, la curatela y la administración legal, en referencia esta última, al supuesto de que la responsabilidad parental fuera ejercida por terceros como instituciones de naturaleza pública y no por los progenitores. Cabría añadir también el derecho de relación, no sólo con los progenitores, sino con otros miembros del círculo familiar como los abuelos o los hermanos.

Se ha buscado en la vigente definición, otorgar la mayor amplitud posible a la misma considerando, como dice Cobo Sáez ${ }^{44}$, que no solo comprende la potestad/función de guarda y custodia, sino también materias tales como la tutela familiar e institucional y el acogimiento residencial o familiar en casos de desamparo.

En efecto, aunque los aspectos mas destacados de la responsabilidad parental ${ }^{45}$ son el derecho de custodia y de visita, aquella no se reduce a éstos, sino que es un concepto más amplio incluso que el tradicional en nuestro derecho civil de la patria potestad. Dentro del

44 Op. cit. , página 68.

45 Véase sobre la cuestión C. Valor Gómez, «La responsabilidad parental en la normativa comunitaria: situación actual y perspectivas de futuro", Jomadas sobre derecho de los menores, / coord. por Isabel E. Lázaro González, Ignacio V. Mayoral Narros, 2003, páginas 213-224. 
mismo se circunscribe un extenso abanico de situaciones, pues la responsabilidad parental puede ser detentada tanto por personas físicas como jurídicas y además, recoge todo lo referente a la guarda o protección de menores, bien en su propio ámbito familiar o de parentesco, o bien en una familia de acogida o en una institución legal.

La responsabilidad parental incide sobre los menores pero es una relación bilateral en la que la otra parte ostenta esa responsabilidad. La conexión entre ambas partes, en principio viene dada por un vínculo parental, pero como ya se ha dicho anteriormente, la regulación del Reglamento tiene una vocación extensiva por lo que se incluye la ostentada, por ejemplo, por instituciones legalmente establecidas para la tutela de los menores. No obstante, la relación de partida sigue siendo la filial, por lo que habrá de definirse también cual es la condición de hijo, es decir, qué debe entenderse por tal. En el Reglamento Bruselas II la noción de hijo se amplia y abarca no sólo a los hijos comunes de una pareja, sino que se extiende a aquellos que son sólo de uno de los cónyuges habidos en uniones anteriores y respecto de los que se establece un vínculo con el nuevo cónyuge del progenitor ${ }^{46}$.

\section{CONCEPTO DE DERECHO DE VISITA}

Para determinarlo es necesario comenzar citando el artículo 8.13 de la Carta Europea de Derechos del Niño de 8 de julio de 1992, que establece que «en caso de separación de hecho, separación legal, divorcio de los padres o nulidad del matrimonio, el niño tiene derecho a mantener contacto directo y permanente con los dos padres teniendo ambos las mismas obligaciones, incluso si alguno de ellos viviese en otro país " ${ }^{47}$. Por su parte el Reglamento define en su artículo 2.10 el derecho de visita como el derecho de trasladar a un menor a un lugar distinto del de su residencia habitual durante un periodo de tiempo limitado. Se encuentra estrechamente vinculado con

46 Dice Puig Blanes, op. cit., página 32, que la noción de hijo abarca lo que se entiende doctrinalmente como "hijos de familia».

47 Sobre esta materia, F. Rivero Hernández, El derecho de visita, Barcelona: José María Bosch, 1997, P. J. Viladrich Bataller, «El derecho de visita de los menores en las crisis matrimoniales: Teoría y praxis», Pamplona: Universidad de Navarra, 1982, M. Moya Escudero, Aspectos internacionales del derecho de visita de los menores, Granada: Comares, 1998, F. R. Hernández, «El derecho de visita. Ensayo de construcción unitaria», El derecho de visita, coord. por Francisco Rivero Hernández, 1997, páginas 31246. 
el derecho de custodia ya que éste atribuye al progenitor custodio la facultad de decidir donde va a residir el menor, lo que puede condicionar la coordinación de la ejecución del régimen de visitas con el otro progenitor. Queda claro pues, que la regulación de las visitas en los casos de crisis matrimoniales es un derecho, no sólo de los padres, sino también de los hijos, si bien, también es necesario especificar que ambas partes no se encuentran en situación de igualdad, sino que, al estar toda la regulación en materia de responsabilidad parental regida por el principio superior de interés o beneficio del menor $^{48}$, si la relación de visitas con los padres no fuera favorable para aquél, podrá ser suprimida o suspendida temporalmente. Es decir, nunca prevalecerá el derecho de visita de los padres sobre el interés general del menor, concepto éste que será valorado por la autoridad competente en cada Estado y que ha de entenderse referido a su bienestar y formación integral.

La definición que aparece en el Reglamento es quizá demasiado escueta y no específica aspectos importantes, tales como si la titularidad sólo se ostenta por los padres o puede corresponder también a otros familiares como los abuelos ${ }^{49}$. Quizá intencionadamente, se ha pretendido regular el concepto de forma extensa a fin de permitir la entrada a las distintas modalidades normativas nacionales que serán las que determinaran los parientes legitimados para ser titulares de este derecho. En el caso de que surgieran discrepancias entre las legislaciones del Estado que dictó la resolución que estableció el derecho de visita y el Estado que deba ejecutarla, prevalecerá lo acordado en la resolución generadora del derecho de visita, adoptada en tal caso, según la legislación de su propio Estado.

48 Sobre esta idea, C. de Diego-Lora, «El menor, centro de atribución de los derechos en las relaciones paterno-filiares», El derecho de visita, coord. por Francisco Rivero Hernández, 1997, páginas 443-454.

49 G. García, Las relaciones familiares entre nietos y abuelos según la Ley de 21 de noviembre de 2003, Madrid: Civitas, 2004, A. M. Colás Escandón, «Relaciones familiares de los nietos con sus abuelos: derechos de visita, estancia, comunicación y atribución de la guarda y custodia: (Ley 42/2003, 21 de noviembre)», Cizur Menor (Navarra): Thomson-Aranzadi, 2005, J. M. Rivera Alvarez, «Reconocimiento judicial del derecho de visita de los abuelos a sus nietos y ejercicio de la patria potestad. Acceso casacional del problema de la extensión del régimen. La disposición transitoria 10. ${ }^{a}$ de la Ley de 13 de mayo de 1981: Comentario a la sentencia del Tribunal Supremo (Sala 1..$^{\text {a) }}$ de 23 de noviembre de 1999", Revista de derecho privado, I Año n. ${ }^{\circ} 85$, Mes 1, 2001, páginas 75-87. M. Carballo Fidalgo, «El 'derecho de visita' de los abuelos y la atribución de la guarda de sus nietros tras la Ley 42/2003, de 21 de noviembre: aspectos sustantivos y procesales», Revista de derecho de familia: Doctrina, Jurisprudencia, Legislación, N. 30, 2006, páginas 45-80 y G. A. Botana García, "Derecho de visita de los abuelos», Actualidad civil, N.º 1, 2004, páginas 548-560. 
A pesar de la definición expresa del derecho de visita, siguen planteándose algunos problemas interpretativos. En este sentido puede citarse a Caro Gándara ${ }^{50}$, que, puesto que el derecho de visita no queda incluido en la definición de traslado o retención ilícitos, plantea el mismo interrogante que se suscitaba con relación al Convenio de La Haya de 1980 sobre sustracción internacional de menores: ¿puede considerarse protegido el derecho de visita mediante las normas que regulan la cooperación de autoridades en materia de sustracción internacional de menores?

La respuesta ha de encontrarse en el contenido y el objeto del Reglamento, cuya regulación y protección del derecho de visita, a diferencia del Convenio de La Haya de 1980, se manifiesta especialmente referida al reconocimiento de resoluciones y por lo tanto, dirigida a procurar la ejecutividad de las resoluciones dictadas a tal efecto por cualquier Estado miembro, en los demás.

\section{CONCEPTO DE DERECHO DE CUSTODIA}

Su definición aparece en el artículo 2.9 que define como derechos de custodia, «entre otros los derechos y obligaciones relativos al cuidado de la persona de un menor y en especial el derecho a decidir sobre su lugar de residencia ${ }^{51}$.

Este derecho que puede venir determinado ex lege o por resolución judicial dictada para el caso concreto, puede ser de titularidad de ambos progenitores conjuntamente o de uno de ellos en el caso de que vivan separados, de los tutores, curadores, personas físicas o jurídicas e instituciones públicas o privadas.

Es una cuestión importante desde el punto del derecho civil sustantivo el resolver la posible confrontación que pueda darse entre esta definición del concepto de visita y los enunciados que del mismo puedan aparecer en los distintos ordenamientos jurídicos nacionales. Las discrepancias en este ámbito se inician, no con respecto a la concreta noción de derecho de custodia o de visita, sino que se gene-

50 Op. cit., página 4704.

51 Sobre este concepto puede verse L. F. Ragel Sánchez, «La guardia y custodia de los hijos», Derecho privado y Constitución, N. ${ }^{\circ} 15,2001$, páginas 281-330, F. Rivero Hernández, «La guarda y custodia de los hijos y derecho de visita tras la crisis matrimonial», La situación jurídica de la mujer en los supuestos de crisis matrimonial: IV Seminario de Estudios Jurídicos, coord. por María Dolores Cervilla Garzón, 1997, páginas 61-134. 
ran en el más amplio concepto de la responsabilidad parental, que si bien equivaldría al de la patria potestad de nuestro derecho civil, no coincide de pleno con su ámbito material. El hecho de la regulación de estas materias en un Reglamento comunitario de directa y obligatoria aplicación, unido al principio de primacía del derecho comunitario, llevan a concluir que habrá de prevalecer este último y los conceptos que establece sobre el derecho civil nacional y en nuestro caso, sobre el derecho civil común o autonómico, cuando se ejecuten las resoluciones de otro Estado miembro ${ }^{52}$.

\section{CONCLUSIONES}

El Reglamento 2201 es un instrumento jurídico fruto de extensos precedentes tanto en el ámbito comunitario como en el internacional, en el que viene a confluir una extensa experiencia jurídica en materia de responsabilidad parental. Su objetivo fundamental es conseguir la armonización de las instituciones jurídicas en materias tan sensibles como la de la protección de los menores, cuya complejidad se manifiesta además, en que si bien su regulación se enmarca preferentemente en el ámbito privado, tiene una significativa vertiente pública por afectar a intereses y principios del orden público internacional, sobre el que los Estados no pueden dejar de ejercer un cierto grado de vigilancia.

El Reglamento 2201 busca la homogeneización a través de la armonización procesal y ésta se basa a su vez en los principios de cooperación y de confianza mutua entre los Estados miembros. Pero no puede desligarse del movimiento general de consolidación de las instituciones de derecho privado en la regulación de sus contenidos materiales, que resulta necesaria para la consecución del objetivo comunitario de creación de un espacio de libertad, seguridad y justicia.

Desde este punto de vista, el Reglamento se rige por el principio de respeto al interés superior del menor, que se refleja en la búsqueda de la igualdad de todos los hijos, en otorgar un destacado papel

52 En este sentido manifiesta P. López Vicente, op. cit., página 117 que: «el ámbito y alcance de la guarda y custodia en nuestro Código Civil....no es totalmente coincidente con los derechos de custodia, en la definición reglamentaria, ya que ésta incluye específicamente el derecho de decidir sobre el lugar de residencia del menor, derecho que en el Código Civil se situaba en principio en el ámbito de la «patria potestad" que les corresponde en principio y con carácter general a los dos progenitores. Con la entrada en vigor del R. 2201/2003 resulta de aplicación en toda su amplitud el nuevo concepto comunitario de custodia». 
procesal al menor a través de su audiencia, en el establecimiento de la residencia habitual del mismo como criterio de determinación de los foros competenciales y por último y fundamentalmente en lo que aquí respecta, se manifiesta también en que la aplicación del Reglamento se extiende a todas las resoluciones en materia de responsabilidad parental de protección del menor, con independencia de que estén vinculadas o no a un procedimiento matrimonial.

La importancia del Reglamento no sólo radica en la consolidación de unas relaciones jurídicas más estrechas entre Estados, sino también en el hecho de que trata materias que afectan directamente a aspectos sustanciales de la vida del ciudadano europeo. En efecto, el garantizar a todos los menores que se hallen en su territorio, un elenco de derechos básicos relativos a la salud, a la integridad física y moral, a la educación y a mantener relaciones con sus progenitores constituye, en definitiva, una manifestación de la defensa de los derechos fundamentales que avalan las instituciones europeas con el TJCE como máximo garante y de la que la Carta de Derechos Fundamentales de la UE es el principal exponente.

\section{BIBLIOGRAFIA}

ALEN, A.,... [et al.], The UN children's Rights Convention: theory meets practice: Proceedings of the International Interdisciplinary Conference on Children's Rights, 18-19 May 2006, Antwerpen: Intersentia, 2007.

BAINHAM, A., "Family rights in the next millennium", Current legal problems, v. 53, 2000, págs. 471-503.

BASEDOW, J., "The comunitarisation of the conflict of law under the Treaty of Amsterdam", $C M L R, 2000$, págs. 687 y siguientes.

BONADUCE, C., "L'interpretazione della Convenzione di Bruxelles del 1968 alla luce del Regolamento n. 44/2001 nelle pronunce della Corte di giustizia", Rivista di diritto internazionale, v. 86, n. 3, 2003, página 746-758.

BONOMI, A., «Il regolamento comunitario sulla competenza e sul riconoscimento in materia matrimoniale e di potestà dei genitori», Rivista di diritto internazionale, v. 84, n. 2, 2001, págs. 298-346.

BORRÁS RODRÍGUEZ, A., REDI, N. 2, 1999, págs. 383 y siguientes, E. Pérez Vera, "El Derecho internacional privado y la Unión Europea», La Unión Europea ante el siglo XxI: los retos de Niza (Actas 
de las XIX Jornadas de la Asociación Española de Profesores de Dereho Internacional y Relaciones internacionales), Madrid, BOE; 2003, págs. 173 y siguientes.

BOTANA GARCÍA, G. A., "Derecho de visita de los abuelos», Actualidad civil, N. ${ }^{\circ} 1,2004$, págs. 548-560.

BRUNEAU, C., «La reconnaissance et l'exécution des décisions rendues dans l'Union européenne", La semaine juridique. Edition générale, n. 17, 25 avril, 2001, págs. 801-808.

BRUNEAU, C. "Le Traité d'Amsterdam et la coopération judiciaire en matière civile. Transformation en règlements communautaires de quatre conventions européennes», La semaine juridique. Edition générale, année 74, n. 43-44, 25 octobre, 2000, págs. 1955-1959.

CALVO BABÍO, F., «El nuevo Reglamento comunitario en materia matrimonial y de responsabilidad parental», Iuris: Actualidad y práctica del derecho, N. ${ }^{\circ} 94,2005$, págs. 42-50.

CALVO BABÍO, F., «Problemas que se han producido en la aplicación judicial del derogado Reglamento (CE) 1347/2000, del consejo, de 29 de mayo del 2000, relativo a la competencia, el reconocimiento y la ejecución de resoluciones judiciales en materia matrimonial y de responsabilidad parental sobre los hijos comunes», Crisis matrimoniales: protección del menor en el marco europeo: (Jornadas de cooperación judicial europea celebradas en Madrid los dias 25, 26 y 27 de octubre 2004), coord. por Anna Quiñones Escámez, Flora Calvo Babío, José Pascual Ortuño Muñoz, 2005, págs. 187-208.

CARBALLO FIDALGO, M.,»El 'derecho de visita' de los abuelos y la atribución de la guarda de sus nietros tras la Ley 42/2003, de 21 de noviembre: aspectos sustantivos y procesales», Revista de derecho de familia: Doctrina, Jurisprudencia, Legislación, N. ${ }^{\circ}$ 30, 2006, págs. 45-80.

CARBONE, S. M., Il nuovo spazio giudiziario europeo dalla Convenzione di Bruxelles al Regolamento CE 44/2001, 4. ed., Torino: Giappichelli, 2002.

CANO BAZAGA, E., «El derecho de familia comunitario: la competencia judicial internacional de los tribunales españoles en materia de crisis matrimoniales y responsabilidad parental», Anuario de derecho europeo, N. ${ }^{\circ} 2,2002$, págs. 67-89 
CARO GÁNDARA, R., «Nuevos desafios comunitarios en materia matrimonial y de responsabilidad parental en las relaciones jurídicas transfronterizas», (Competencia judicial internacional, reconocimiento y ejecución de resoluciones en materia de familia y sustracción internacional de menores a la luz del Reglamento 2201/2003), Estudios Jurídicos (2004) página 4695-4731. Disponible en <http:www.cej.justicia.es/pdf/publicaciones/secretariosjudiciales/SECJUD11.pdf

CARO GÁNDARA, R., "Algunos problemas derivados del ámbito de aplicación personal del Reglamento $1347 / 2000$ relativo a la competencia judicial, reconocimiento y ejecución de resoluciones judiciales en matera matrimonial y de responsabilidad parental sobre los hijos comunes", Revista de derecho de familia: Doctrina, Jurisprudencia, Legislación, n. ${ }^{\circ}$ 14, 2002, págs.. 259-270.

COBO SÁENZ, J.F., «El reconocimiento y ejecución de resoluciones judiciales, documentos públicos y acuerdos enre las partes con fuerza ejecutiva, en el Reglamento CE número 2201/03, (Bruselas II), relativo a la competencia judicial, el reconocimiento y la ejeución de resoluciones en materia matrimonial y de responsabilidad parental», Cooperación judicial en materia de familia y relaciones parentales en la UE, Madrid: CGPJ, 2006, págs. 49-98.

COLÁS ESCANDÓN, A. M., "Relaciones familiares de los nietos con sus abuelos: derechos de visita, estancia, comunicación y atribución de la guarda y custodia: (Ley 42/2003, 21 de noviembre)», Cizur Menor (Navarra): Thomson-Aranzadi, 2005.

CORDERO ALVAREZ, C. I., «Crisis matrimoniales y responsabilidad parental dentro y fuera de la Unión Europea: el Código de Familia Comunitario», Anuario jurídico y económico escurialense, n. ${ }^{\circ} 39,2006$, págs. $215-258$

DIAGO DIAGO, M. P., «El derecho de los hijos a mantener relaciones personales con ambos progenitores. A propósito de la propuesta de Reglamento del Consejo relativo a la competencia, el reconocimiento y la ejecución de resoluciones judiciales en materia matrimonial y de responsabilidad parental y su extensión a la sustracción de menores", Cursos de derechos humanos de Donostia-San Sebastián, Vol. 4, 1999, págs. 205-220

DE DIEGO-LORA, C., «El menor, centro de atribución de los derechos en las relaciones paterno-filiares», El derecho de visita, coord. por Francisco Rivero Hernández, 1997, págs. 443-454 
DI LIETO, A., «Il regolamento n. 2201/2003 relativo alla competenza, al riconoscimento e all'esecuzione delle decisioni in materia matrimoniale e in materia di responsabilità genitoriale», Diritto comunitario e degli scambi internazionali, anno 43, n. 1, gennaiomarzo, 2004, págs. 117-137

DE MIGUEL ASENSIO, P.A., «Integración europea y Derecho internacional privado», $R D C E, N .^{\circ} 2,1997$, págs. 413 y siguientes, ibid., "La evolución del Derecho internacional privado comunitario en el Tratado de Ámsterdam», redi, 1998-1, págs. 373 y siguientes.

DOMINGO MONFORTE, J.,»Regímenes de visitas transfronterizos: responsabilidad parental", Actualidad jurídica Aranzadi, N. ${ }^{\circ} 714$, 2006, págs. $1-7$

DURÁN AYAGO A., «El interés del menor en el conflicto de civilizaciones. Elementos para su concreción en un contexto intercultural», en Calvo Caravaca, A-L. y Castellanos Ruiz, E. (dir.), El derecho de familia ante el siglo XxI: Aspectos internacionales, Madrid, Colex, 2003, págs. 295 y siguientes.

ESTEBAN DE LA ROSA, G., El acogimiento internacional de menores. Régimen jurídico, Granada: Comares, 2000.

FORCADA MIRANDA, F. J., «Normativa de la Unión Europea en materia de Derecho de familia: el Reglamento sobre competencia, reconocimiento y ejecución de resoluciones en materia matrimonial y de responsabilidad parental», Práctica de tribunales: revista de derecho procesal civil y mercantil, N. ${ }^{\circ} 28,2006$, págs. $32-47$

FRANZINA, P., «Le condizioni di applicabilità del regolamento (CE) n. 44/2001 alla luce del parere 1/03 della Corte di giustizia»,: Rivista di diritto internazionale, v. 89, n. 4, 2006, págs. 948-977

FRANZINA, P., «Il coordinamento fra «lex fori» e norme uniformi nell'accertamento del titolo di giurisdizione secondo il regolamento (CE) N. 44/2001", Rivista di diritto internazionale, v. 87, n. 2, 2004, págs. 345-392

GARAU SOBRINO, F. F., "El ámbito de aplicación del reglamento $1347 / 2000$ en materia matrimonial y de responsabilidad parental sobre los hijos comunes", El derecho de familia ante el siglo XXI: aspectos internacionales, coord. por Esperanza Castellanos Ruiz, Alfonso Luis Calvo Caravaca, 2004, págs. 399-410

GARCÍA, G., Las relaciones familiares entre nietos y abuelos según la Ley de 21 de noviembre de 2003, Madrid: Civitas, 2004. 
GARCÍA CANO, S., „Derecho internacional privado: Un nuevo instrumento internacional en la regulación del derecho de visita: el convenio del Consejo de Europa sobre las relaciones personales del menor de 15 de mayo de 2003", Revista española de derecho internacional, Vol. 57, N. ${ }^{\circ}$ 2, 2005, págs. 1166-1179

GARDEÑES SANTIAGO, M., "El desarrollo del Derecho internacional privado tras el Tratado de Ámsterdam: los artículos 61 c) y 65 TCE como base jurídica», $R D C E$, num. 11, mayo-agosto 2002, págs. 231 y siguientes.

GAUDEMET-TALLON, H., Compétence et exécution des jugements en Europe: Règlement n. 44/2001, Conventions de Bruxelles et de Lugano, 3e éd, Paris: LGDJ, 2002.

GAUDEMET-TALLON, H., "Le Règlement $n^{\circ}$ 1347/2000 du Conseil du 29 mai 2000: «compétence, reconnaissance et exécution des décisions en matière matrimoniale et en matière de responsabilité parentale des enfant communs", Joumal du droit international, v. 128 , n. 2, 2001, págs. 381-445

GONZÁLVEZ VICENTE, P., «El reglamento (CE) 2201/2003: el alcance del reconocimiento mutuo de las decisiones sobre el derecho de visita y secuestro de menores», Estudios de derecho judicial, N. ${ }^{\circ} 74,2005$, págs. 101-144

HERNÁNDEZ, F. R. «El derecho de visita. Ensayo de construcción unitaria", El derecho de visita, coord. por Francisco Rivero Hernández, 1997, págs. 31-246

LÓPEZ VICENTE, «El Reglamento (CE) 2201/2003: el alcance del reconocimiento mutuo de las Decisiones sobre el Derecho de visita y secuestro de menores», Cooperación judicial en materia de familia y relaciones parentales en la UE, Madrid: CGPJ, 2006, página 101147.

MANSI, F. P., «Il giudice italiano e le controversie europee: dalla Convenzione di Bruxelles del 1968 alla Convenzione di Lugano del 1988 ed al Regolamento (CE) n. 44/2001», Milano: Giuffrè, 2004.

MOYA ESCUDERO, M., "Competencia judicial y reconocimiento de decisiones en materia de responsabilidad parental: el reglamento Bruselas II», La cooperación judicial en materia civil y la unificación del derecho privado en Europa / coord. por Mercedes Moya Escudero, Sixto Alfonso Sánchez Lorenzo, 2003, págs. 105-130 
MOYA ESCUDERO, M, Aspectos internacionales del derecho de visita de los menores, Granada: Comares, 1998.

NUYTS, A., «La communautarisation de la convention de Bruxelles: le règlement 44/2001 sur la compétence judiciaire et l'effet des décisions en matière civile et commerciale», Journal des tribunaux, v. 120, n. 6035, 2001, págs. 913-922

ORTUÑO MUÑOZ, P., «Competencia judicial internacional y reconocimiento de decisiones en materia de protección de menores. Aplicación conjunta de distintos instrumentos internacionales. Reglamento (CE) 2201/2003", Cooperación judicial en materia de familia y relaciones parentales en la UE, Madrid: CGPJ, 2006, página 147-185.

PILOTTI, F., Globalización y convención sobre los derechos del Niño: el contexto del texto, Santiago de Chile: CEPAL, 2001.

PUERTO MENDOZA, M. L., «La libre circulación de resoluciones judiciales sobre responsabilidad parental dentro de la Unión Europea», La Ley: Revista jurídica española de doctrina, jurisprudencia y bibliografía, ISSN 0211-2744, N. 5, 2002, págs. 1692-1699

PUIG BLANES, F.P., , Competencia judicial y foros de competencia en el Reglamento (CE) n. ${ }^{\circ} 2201 / 2003$ del Consejo, de 27 de noviembre de 2003, relativo a la competencia, el reconocimiento y la ejecución de resoluciones judiciales en materia matrimonial y de responsabilidad parental, por el que se deroga el Reglamento (CE) n. ${ }^{\circ}$ 1347/2000", Cooperación judicial en materia de familia y relaciones parentales en la UE, Madrid: CGPJ, 2006, págs. 15-47

QUIÑONES ESCÁMEZ, A., "Competencia judicial internacional en materia de responsabilidad parental y sustracción de menores en el Reglamento 2201/2003», Crisis matrimoniales: protección del menor en el marco europeo: (Jornadas de cooperación judicial europea celebradas en Madrid los días 25, 26 y 27 de octubre 2004), coord. por Anna Quiñones Escámez, Flora Calvo Babío, José Pascual Ortuño Muñoz, 2005, págs. 103-136

RAGEL SÁNCHEZ, L. F., "La guardia y custodia de los hijos», Derecho privado y Constitución, N. ${ }^{\circ} 15,2001$, págs. 281-330

RIVERA ALVAREZ, J. M.,»Reconocimiento judicial del derecho de visita de los abuelos a sus nietos y ejercicio de la patria potestad. Acceso casacional del problema de la extensión del régimen. La disposición transitoria $10 .^{a}$ de la Ley de 13 de mayo de 1981: Comentario a la sentencia del Tribunal Supremo (Sala 1. ${ }^{a}$ ) de 23 
de noviembre de 1999", Revista de derecho privado, IAño n. ${ }^{\circ} 85$, Mes 1, 2001, págs. 75-87

RIVERO HERNÁNDEZ, F., El derecho de visita, Barcelona: José María Bosch, 1997.

RIVERO HERNÁNDEZ, F.,»La guarda y custodia de los hijos y derecho de visita tras la crisis matrimonial», La situación jurídica de la mujer en los supuestos de crisis matrimonial: IV Seminario de Estudios Jurídicos, coord. por María Dolores Cervilla Garzón, 1997, págs. 61-134

RODRÍGUEZ PINEAU, E., «Reconocimiento y ejecución de resoluciones en materia de responsabilidad parental en el Reglamento 2201/2003", Crisis matrimoniales: protección del menor en el marco europeo: (Jornadas de cooperación judicial europea celebradas en Madrid los dias 25, 26 y 27 de octubre 2004), coord. por Anna Quiñones Escámez, Flora Calvo Babío, José Pascual Ortuño Muñoz, 2005, págs. 137-165

ROSENBLATT, J., International conventions affecting children, Dordrecht; Boston: Kluwer Law International, 2000.

RUBIO TORRANO, E., «Conflictos matrimoniales y responsabilidad parental: nuevo Reglamento comunitario», Aranzadi civil, N. ${ }^{\circ} 3$, 2003, págs. 2102-2104

SABIDO RODRÍGUEZ, M., «La sustracción de menores en derecho internacional privado español: algunas novedades que introduce el reglamento 2201/03", Anuario de la Facultad de Derecho, N. ${ }^{\circ} 22$, 2004, págs. $307-320$

SIANI, V., «Il regolamento CE n. 44/2001 sulla competenza giurisdizionale e sull'esecuzione delle sentenze. Parte prima, La cooperazione giudiziaria in materia civile e commerciale: dalla Convenzione di Bruxelles al regolamento (CE) n. 44/2001», Diritto comunitario e degli scambi internazionali, anno $42, n$. 3, luglio-settembre, 2003, págs. 451-534

STADLER, A., «From the Brussels Convention to regulation 44/2001: cornerstones of a European law of civil procedure», Common Market Law Review, v. 42, n. 6, December, 2005, págs. 1637-1661.

STERN, R.,The child's right to participation [on-line]: reality or rhetoric?, Uppsala: Acta Universitatis Upsaliensis, 2006, $<$ http://urn.kb.se/resolve?urn=urn:nbn:se:uu:diva-7083> 
TAGARAS, $\mathbf{H}$., «La révision et communautarisation de la Convention de Bruxelles par le règlement 44/2001», Cahiers de droit européen, v. 39 , n. 3-4, 2003, págs. 399-432

UCCELLA, F., Il diritto comunitario sulle decisioni in materia matrimoniale e di responsabilità genitoriale: regolamento $(\mathrm{CE}) \mathrm{n}$. 2201/2003 del 27 novembre 2003, relativo alla competenza, al riconoscimento e all'esecuzione delle decisioni in materia matrimoniale e in materia di responsabilità genitoriale, Salerno: Edisud, 2005

VALOR GÓMEZ, C., «La responsabilidad parental en la normativa comunitaria: situación actual y perspectivas de futuro», Jornadas sobre derecho de los menores, / coord. por Isabel E. Lázaro González, Ignacio V. Mayoral Narros, 2003, págs. 213-224.

VILADRICH BATALLER, P. J., «El derecho de visita de los menores en las crisis matrimoniales: Teoría y praxis», Pamplona: Universidad de Navarra, 1982.

WATTÉ, N., Boularbah, H., «Les nouvelles règles de conflits de juridictions en matière de désunion des époux: le règlement communautaire «Bruxelles II», Journal des tribunaux, année 120, n. 6009, 28 avril, 2001, págs. 369-378.

ZARRALUQUI SÁNCHEZ-EZNARRIAGA, L., "Disponibilidad del objeto en los procesos familiares: especial consideración de la custodia de los hijos», Temas actualidad derecho familia, coord. por Luis Zarraluqui Sánchez-Eznarriaga, 2006, págs. 13-84 